\title{
Editorial
}

\section{Del reporte de caso a otros diseños}

\section{From Case Reports to other Designs}

\author{
Herney Andrés García-Perdomo ${ }^{1}$ \\ ${ }^{1}$ Escuela de Medicina, Universidad del Valle, Cali, Colombia \\ Urol Colomb 2019;28:3-4.
}

Entramos en una nueva era de la política editorial en la que sólo los reportes de caso no son suficientes. Ellos nacieron para poder describir aquellos casos relevantes e importantes o aquellos que por primera vez salen a la luz y que pueden servir para que los colegas aprendan dada la poca frecuencia de su presentación. Sin embargo, en la actualidad, los reportes de caso deben ser publicados sólo en casos muy seleccionados y bajo unas condiciones de muy poca frecuencia o alta relevancia para la literatura mundial. ${ }^{1}$

Por otro lado, contamos con diferentes diseños epidemiológicos que pueden servir para mejorar nuestra visibilidad como urólogos, así como la de la revista Urología Colombiana. Entre ellos cuentan: Los observacionales descriptivos (series de caso y corte transversal), los observacionales analíticos (Casos y controles; Cohortes), los experimentales y la síntesis de evidencia (Revisiones sistemáticas/meta-análisis; Revisión de revisiones; Scoping review).

Si estamos iniciando con la investigación en un solo centro asistencial, se podría iniciar con una serie de casos, describir o caracterizar una población con un objetivo claro. Incluso, se podrían unir esfuerzos con otra institución para incrementar así el tamaño de muestra y publicar una serie de muchos más casos con mayor extrapolación a nuestra población. ${ }^{1}$ Por otro lado, se podría obtener la prevalencia de una condición específica (Corte transversal), en esa serie de casos e incluso poder realizar un análisis un poco más profundo entre las variables diferentes entre un grupo y el otro. ${ }^{2}$

Teniendo bases de datos, se podría obtener un grupo que tenga un evento o condición y otro que no lo tenga (Casos y controles), e identificar factores que hayan estado asociados a un grupo u otro, así, se obtiene información fundamental para ver los riesgos y poder prevenir enfermedades en el futuro u obtener el pronóstico. ${ }^{2}$ El diseño de casos y controles, aunque con mayor riesgo de sesgo, tiene la posibilidad de ser realizado con poco recurso económico. Si contamos con uno o varios grupos cautivos y expuestos a ciertos factores, se podría realizar un seguimiento a largo plazo evaluando si presentan o no un desenlace específico (Cohortes). ${ }^{3}$ Este diseño, aunque costoso es uno de los más relevantes en términos de la identificación de factores etiológicos.

Si se cuenta con mayor experiencia, se podría unir diferentes centros asistenciales, varios colegas que les guste trabajar en equipo para probar una intervención, se aleatorizan pacientes con una condición específica a una intervención u otra (Experimento clínico), y se evalúa el desenlace final. ${ }^{4}$ Ese tipo de diseño, tiene mayores exigencias pero es factible después de tener la asesoría y los permisos pertinentes para su realización en cada uno de los centros nacionales e internacionales en los que se quiera realizar.

Adicionalmente contamos con la síntesis de evidencia, específicamente con las revisiones sistemáticas, desarrolladas para realizar una evaluación exhaustiva, sistemática y explícita de la literatura, de acuerdo con una pregunta de investigación clara, una metodología explícita, una evaluación crítica de cada estudio y una descripción cualitativa de la evidencia. ${ }^{5}$ El meta-análisis (MA), por otro lado, es el análisis estadístico utilizado en esos estudios en tal caso que sea posible su realización. ${ }^{5}$

Contamos además con las revisiones narrativas, generalmente escrito por personas de amplia experiencia, se trata de un manuscrito que describe un tema específico, sin una estrategia clara para obtener la información ni para plasmarla en un documento. Sin embargo, muy necesario para estudiantes de pre y posgrado, quienes de manera rápida quisieran acceder a un escrito de un tema particular que los guíe y les genere mayores preguntas. ${ }^{6}$

Escribir no es fácil, como toda habilidad, requiere un entrenamiento específico y un apoyo dado por personas con más experiencia. De tal manera que cuando lo requieran, pidan ayuda a aquellos que ya han realizado estudios y ya tienen más práctica escribiendo y publicando, para que entre todos incrementemos la calidad y transparencia de las publicaciones en nuestra prestigiosa revista.

\author{
Address for correspondence DOI https://doi.org/ \\ Herney Andrés García-Perdomo, $\quad$ 10.1055/s-0039-1677860. \\ MD, MSc, EdD, PhD, FACS, Escuela ISSN 0120-789X. \\ de Medicina, Universidad del elSSN 2027-0119.
}

Valle, Cali, Colombia

(e-mail: Herney.garcia@

correounivalle.edu.co).
Copyright $\odot$ 2019, Sociedad Colombiana License terms de Urología. Publicado por Thieme Revinter Publicações Ltda., Rio de Janeiro, Brazil. Todos los derechos reservados. 


\section{Bibliografía}

1 Romaní Romaní F. Reporte de caso y serie de casos: una aproximación para el pregrado. CIMEL Cienc e Investig Médica Estud Latinoam. 2010;15(01):46-51

2 Ruiz Morales A. Epidemiologia clinca: investigacion clinica aplicaa. 2004:625

3 Lazcano-Ponce E, Fernández E, Salazar-Martínez E, HernándezAvila M. Estudios de cohorte. Metodología, sesgos y aplicación. Salud Publica Mex 2000;42(03):230-241
4 Friedman L, Furberg C, DeMets D. Fundamentals of Clinical Trials. 3rd ed. New york: Springer; 1998

5 García-Perdomo HA. Evidence synthesis and meta-analysis: a practical approach. Int J Urol Nurs 2015. Doi: https://doi.org/ 10.1111/ijun.12087

6 Aguilera Eguía R. ¿Revisión sistemática, revisión narrativa o metaanálisis? Rev Soc Esp Dolor 2014;21(06):359-360 